\title{
A Retrospective Analysis of Three Non-Invasive Tests for Initial Diagnosis of Helicobacter pylori Infection in Children
}

\author{
Tamaki Ikuse ${ }^{1,2}$, Takahiro Kudo ${ }^{1}$, Naho Obayashi' ${ }^{1}$, Keisuke Jimbo' ${ }^{1}$, Yo Aoyagi ${ }^{1}$, \\ Yoshikazu Ohtsuka1, Thomas G. Blanchard ${ }^{2}$, Steven J. Czinn' ${ }^{2}$, Toshiaki Shimizu${ }^{1}$ \\ ${ }^{1}$ Department of Pediatric and Adolescent Medicine, Juntendo University Graduate School of Medicine, Tokyo, Japan \\ ${ }^{2}$ Department of Pediatrics, University of Maryland School of Medicine, Baltimore, USA \\ Email: taikuse@juntendo.ac.jp
}

How to cite this paper: Ikuse, T., Kudo, T., Obayashi, N., Jimbo, K., Aoyagi, Y., Ohtsuka, Y., Blanchard, T.G., Czinn, S.J. and Shimizu, T. (2017) A Retrospective Analysis of Three Non-Invasive Tests for Initial Diagnosis of Helicobacter pylori Infection in Children. Advances in Microbiology, 7, 253-264.

https://doi.org/10.4236/aim.2017.74021

Received: March 1, 2017

Accepted: April 16, 2017

Published: April 19, 2017

Copyright $\odot 2017$ by authors and Scientific Research Publishing Inc. This work is licensed under the Creative Commons Attribution International License (CC BY 4.0).

http://creativecommons.org/licenses/by/4.0/

\begin{abstract}
Proper diagnosis in the pediatric population is required to eradicate Helicobacter pylori ( $H$. pylori) and prevent gastric cancer. Our aim was to assess the performance of non-invasive tests to diagnose $H$. pylori infection in pediatric patients. A retrospective analysis was performed on 141 pediatric patients requiring endoscopic evaluation and diagnostic tests for $H$. pylori infection to define the cause of abdominal symptoms. Non-invasive tests included the ${ }^{13} \mathrm{C}$-urea breath test (UBT), a monoclonal stool antigen test using enzymelinked immuno-sorbent assay (mSAT), and a serum immunoglobulin G antibody test using antigens derived from Japanese individuals (S-Ab). This study investigated sensitivity, specificity, likelihood ratios for a positive and a negative test $\left(\mathrm{LR}_{+}\right.$and $\left.\mathrm{LR}_{-}\right)$, and accuracy of non-invasive tests, in comparison with invasive tests. Eighty two of 141 patients (58\%) were recognized as $H$. pylori positive by invasive methods. When UBT, mSAT or S-Ab were analyzed, all were found to be effective over $94 \%$ accurate. Specificity ranged between $86.7 \%$ and $95.8 \%$, and sensitivity ranged between $93.8 \%$ and $97.1 \%$. When subjects were stratified into three distinct age groups, the best performance was achieved for 1 - 6 years old with mSAT at 100\% for sensitivity, specificity, and accuracy. S-Ab yielded the best results for children $7-12$ years old and the UBT test performed best for 13 - 18 years old. These results demonstrate the utility of UBT, mSAT, and S-Ab non-invasive tests in diagnosing $H$. pylori but suggest that certain tests may be optimal for children of distinct ages. Three non-invasive tests, UBT, mSAT and S-Ab showed sufficient sensitivity, specificity and accuracy for the initial diagnosis of $H$. pylori infection among pediatric patients. Non-invasive tests may contribute to achieving minimum invasive diagnosis with combining with a histological test and a culture test in children.
\end{abstract}




\section{Keywords}

Accuracy, Non-Invasive Tests, Urea Breath Test, Stool Antigen Test, Serum Antibody Test

\section{Introduction}

Helicobacter pylori (H. pylori) is a microaerophilic Gram-negative spiral bacterial pathogen that resides in the stomach. Their production of urease helps protect the bacteria from the highly acidic environment. H. pylori infection is generally acquired in childhood and typically persists for life. H. pylori infection causes chronic gastric mucosal inflammation that is a risk factor for gastric cancer and the expression of the CagA oncoprotein is common [1]. Eradication therapy before the severe expansion of gastric atrophy is significantly beneficial in the prevention of gastric cancer [2] [3] [4] [5]. Therefore, early eradication therapy especially in early childhood may contribute to reduction in the incidence of gastric cancer. To eradicate $H$. pylori and prevent gastric cancer, proper diagnosis in the pediatric population is required.

Endoscopy remains the gold standard for diagnosis of $H$. pylori infection. There are however, several non-invasive diagnostic tools to detect $H$. pylori infection and these types of tests would be most desirable if their accuracy was shown to be comparable to invasive tests. There are predominantly three types of non-invasive tests used in Japan for the diagnosis of $H$. pylori. These tests include measuring specific antibodies in serum and urine using antigens derived from Japanese individuals, identifying $H$. pylori antigen in the stool using monoclonal antibodies, and the urea breath test. Although several studies have assessed the accuracy of the non-invasive methods, there has been no direct comparison of these three non-invasive methods in the same study in conjunction with diagnosis determined by invasive tests in Japan. The aim of this study was to perform a retrospective study to assess the accuracy of the ${ }^{13} \mathrm{C}$-urea breath test (UBT), a monoclonal stool antigen test using enzyme-linked immuno-sorbent assay (ELISA) tests (mSAT), and a serum specific immunoglobulin $\mathrm{G}(\operatorname{IgG})$ antibody test against $H$. pylori using antigens derived from Japanese individuals (Serum Antibody Test: S-Ab) for the diagnosis of $H$. pylori pediatric patients already screened by endoscopy.

\section{Methods}

\subsection{Patients}

Esophagogastroduodenoscopy (EGDs), all diagnostic tests of $H$. pylori infection and eradication therapies were performed in Juntendo University Hospital in Tokyo, Japan. Subjects consisted of pediatric patients requiring endoscopic evaluation and diagnostic tests for $H$. pylori infection to define the cause of suffering from abdominal symptoms such as epigastralgia, nausea and vomiting. 
Patients were excluded in the case of previous $H$. pylori eradication therapy, consumption of antibiotics or antacid agents in the previous 4 weeks of any examinations. Sample collection for the non-invasive tests was performed within a few days before or after EGDs. A signed informed consent was obtained from the parents of all children before assessment with EGDs.

\subsection{Diagnosis of $H$. pylori Infection}

Two gastric biopsy samples were taken endoscopically from both the antrum and the corpus of stomach for bacterial culture and histologic examination. All patients had no history of $H$. pylori eradication therapy. Positive $H$. pylori status was defined as a positive by either culture or histology. A negative $H$. pylori status was confirmed when both culture and histology gave concordant negative results.

\subsection{UBT}

Patients were fasted for at least 4 hours and then ${ }^{13} \mathrm{C}$-labeled urea dissolved in water was given without taking any test meals. The dose of ${ }^{13} \mathrm{C}$-urea was $100 \mathrm{mg}$ for patients 12 years old or older, $75 \mathrm{mg}$ for 6 - 11 years old patients, and $50 \mathrm{mg}$ for patients less than 6 years old. To reduce the effect of urease-producing oral bacteria, patients rinsed their mouths with water immediately after ingestion of ${ }^{13} \mathrm{C}$-urea. Breath samples were collected in duplicate before ingestion of the ${ }^{13} \mathrm{C}$-urea and at 20 minutes afterwards. Breath samples were analyzed by carbon dioxide carbon isotope ratio analyzer (Spectral Analyzer POCone; Otsuka Electronics Co., Ltd., Osaka, Japan). The cut off value of $\Delta{ }^{13} \mathrm{C}$ was defined to be $3.5 \%$ [6].

\subsection{H. pylori Stool Antigen Test: mSAT}

The mSAT was performed using commercial ELISA tests (Meridian HpSA ELISA II; Meridian Bioscience Inc., Ohio, USA). This test utilizes a panel of monoclonal anti- $H$. pylori capture antibodies adsorbed to microplate wells. The assay was performed according to manufacturer's instructions. An absorbance at $450 \mathrm{~nm}$ of $<0.140$ was defined as negative, and $\geq 0.140$ was defined as positive.

\subsection{Serum Anti-H. pylori IgG Antibody Test: S-Ab}

Serum IgG antibodies to $H$. pylori were measured using commercial EIA tests using antigens derived from Japanese individuals (E plate Eiken H. pylori Antibody II; Eiken Chemical Co., Ltd., Tokyo, Japan). Assays were performed according to manufacturer's instructions. A concentration of anti-H. pylori IgG antibody of $<10 \mathrm{U} / \mathrm{mL}$ was defined as negative, and of $\geq 10 \mathrm{U} / \mathrm{mL}$ was defined as positive.

\subsection{Statistical Analysis}

Sensitivity, specificity, likelihood ratios for a positive and a negative test $\left(\mathrm{LR}_{+}\right.$ and $\mathrm{LR}_{-}$), and accuracy were calculated using standard methods. 


\subsection{Conflicts of Interest}

No specific industry was linked to our study. The authors declare no conflicts of interest.

\section{Results}

The results from 141 pediatric patients examined from 1998 to 2016 by EGDs, $H$. pylori culture examinations and non-invasive $H$. pylori diagnostic tests were assessed. The population consisted of 68 boys and 73 girls with a mean age of $11.77 \pm 3.45$ years (range, 1.33 to 18.92). Eighty-two patients (58\%) were found to be $H$. pylori positive by $H$. pylori culture and/or histological examination. The UBT was used on 100 patients from 1998 to 2016, the mSAT was used on 56 patients from June, 2007 to 2016, and the S-Ab test was given to 92 patients from September $20^{\text {th }}, 2005$ to 2016 . The characteristics of the 141 patients are presented in Table 1. The UBT, mSAT and S-Ab tests were positive in $70 \%, 57.1 \%$, and $55.4 \%$ of children, respectively. The sensitivity, specificity, $L_{+}, L_{-}$and accuracy of the different noninvasive tests on this population when compared to the EGDs/Histology analysis are presented in Table 2. The parameter values indicating performance for each of the three tests were similar. The accuracy for all three tests was at least $94 \%$. The UBT was found to have the highest sensitivity at $97.1 \%$, but even the test with the lowest sensitivity, the mSAT test was $93.8 \%$. The mSAT test however was demonstrated to have the highest specificity at $95.8 \%$ whereas the UBT test was the least specific at $86.7 \%$.

Table 1. Characteristics of 141 pediatric patients.

\begin{tabular}{ccc}
\hline & Number of patients & Rate of H. pylori Infection \\
\hline Total & 141 & $58.2 \%$ \\
Gender & 68 & $61.8 \%$ \\
Male & 73 & $54.8 \%$ \\
Female & & \\
Age (years) & 16 & $43.8 \%$ \\
$1-6$ & 57 & $57.9 \%$ \\
$7-12$ & 68 & $61.8 \%$ \\
$13-18$ & & $70.0 \%$ \\
Non-invasive test & 100 & $57.1 \%$ \\
UBT & & $55.4 \%$ \\
Mean age (years): $12.21 \pm 3.11$ & 56 & \\
mSAT & & \\
Mean age (years): $11.87 \pm 3.16$ & 92 & \\
\hline${ }^{13}$ C-urea breath test, UBT; monoclonal stool antigen test, mSAT; serum antibody test, S-Ab.
\end{tabular}


Table 2. Performance of the non-invasive diagnostic tests.

\begin{tabular}{cccc}
\hline & UBT & mSAT & S-Ab \\
\hline Sensitivity & $97.1 \%$ & $93.8 \%$ & $96.1 \%$ \\
Specificity & $86.7 \%$ & $95.8 \%$ & $95.1 \%$ \\
LR $_{+}$ & 7.29 & 22.5 & 19.7 \\
LR & 0.033 & 0.065 & 0.041 \\
Accuracy & $94.0 \%$ & $94.6 \%$ & $95.7 \%$ \\
\hline
\end{tabular}

${ }^{13} \mathrm{C}$-urea breath test, UBT; monoclonal stool antigen test, mSAT; serum antibody test, $\mathrm{S}$-Ab; likelihood ratio for a positive test, $\mathrm{LR}_{+}$; likelihood ratio for a negative test, $\mathrm{LR}$.

There were 36 patients (mean age, $11.66 \pm 3.06$ years; range, 4.83 to 18.92 ) that underwent all three non-invasive tests. The sensitivity, specificity, $\mathrm{LR}_{+}, \mathrm{LR}_{-}$ and accuracy of the different tests in these 36 patients are presented in Table 3. Within this group, the accuracy of the S-Ab test increased to $97.2 \%$ whereas the accuracy of the UBT test fell to $91.7 \%$. The mSAT remained the same (94.4\%). The sensitivity of all three tests was all similar (95.5\%, 95.8\%, and 95.8\%). The specificity however varied greatly with the UBT falling to $83.3 \%$ and the S-Ab test at $100 \%$. We then divided the 141 patients into 3 groups according to their ages. Group I included 16 patients from 1 to 6 years old with a mean age of 4.95 \pm 1.73 years (range, 1.33 to 6.67). Group II included 57 patients 7 to 12 years old with mean age of $10.44 \pm 1.77$ years (range, 7.00 to 12.92). Group III included 68 patients 13 to 18 years old with mean age of $14.48 \pm 1.21$ years (range, 13.00 to 18.92). The values of the non-invasive tests when assessed by the patient age are described in Table 4. The best performance was observed in Group I where the mSAT test sensitivity, specificity, and accuracy of $100 \%$. The UBT test performed best on Group III with sensitivity, specificity, and accuracy at 97.2, 100, and $98 \%$ respectively, although both the mSAT and S-Ab test each performed well in this group as well.

\section{Discussion}

There are two categories of examinations for detection of $H$. pylori infection, invasive methods and non-invasive methods. Invasive tests require samples taken from the gastric mucosa by EGDs for assessment of $H$. pylori on the mucosa directly. In contrast, non-invasive tests are performed using breath, stool, serum or urine, and assess general changes in the host due to H. pylori infection. There is no single test with $100 \%$ sensitivity and specificity. Culture is the only test with $100 \%$ specificity, however, its sensitivity is lower than other tests [7] [8]. Moreover, we should understand the factors that can lead to a false-positive or falsenegative. Administration of antibiotics or antacid agents within 2 - 4 weeks of testing may result in a false-negative in all tests except for antibody examination [9] [10] [11]. In addition, the accuracy of UBT and antibody tests may be influenced by the age of the tested child [12]. The evidence-based guidelines from ESPGHAN and NASPGHAN [13] recommend the initial diagnosis of $H$. pylori 
Table 3. Characteristics of 36 patients who underwent all 3 non-invasive tests and performance of the non-invasive diagnostic tests.

\begin{tabular}{cccc}
\hline & Number of patients & Rate of $H$. pylori Infection & Mean age (years) \\
\hline Total & 36 & $66.7 \%$ & $11.66 \pm 3.06$ \\
Gender & & & \\
Male & 20 & $60.0 \%$ & $11.56 \pm 2.77$ \\
Female & 16 & $75.0 \%$ & $11.78 \pm 3.57$ \\
& UBT & mSAT & S-Ab \\
Sensitivity & $95.5 \%$ & $95.8 \%$ & $95.8 \%$ \\
Specificity & $83.3 \%$ & $91.7 \%$ & $100 \%$ \\
LR & 5.75 & 11.5 & $\infty$ \\
LR_ & 0.050 & 0.045 & 0.041 \\
Accuracy & $91.7 \%$ & $94.4 \%$ & $97.2 \%$ \\
\hline
\end{tabular}

${ }^{13} \mathrm{C}$-urea breath test, UBT; monoclonal stool antigen test, mSAT; serum antibody test, $\mathrm{S}$ - Ab; likelihood ratio for a positive test, $\mathrm{LR}_{+}$; likelihood ratio for a negative test, $\mathrm{LR}$.

Table 4. Characteristics of three groups divided according to the ages and performance of the non-invasive diagnostic tests.

\begin{tabular}{|c|c|c|c|}
\hline Group I & Number of patients & Rate of Infection & Mean age (years) \\
\hline Total & 16 & $43.8 \%$ & $4.95 \pm 1.73$ \\
\hline \multicolumn{4}{|l|}{ Gender } \\
\hline Male & 9 & $22.2 \%$ & $4.58 \pm 1.80$ \\
\hline \multirow[t]{2}{*}{ Female } & 7 & $71.4 \%$ & $5.42 \pm 1.63$ \\
\hline & UBT & mSAT & $\mathrm{S}-\mathrm{Ab}$ \\
\hline Sensitivity & $83.3 \%$ & $100 \%$ & $75.0 \%$ \\
\hline Specificity & $66.7 \%$ & $100 \%$ & $100 \%$ \\
\hline $\mathrm{LR}_{+}$ & 2.5 & $\infty$ & $\infty$ \\
\hline $\mathrm{LR}_{-}$ & 0.25 & 0 & 0.25 \\
\hline Accuracy & $77.8 \%$ & $100 \%$ & $87.5 \%$ \\
\hline Group II & Number of patients & Rate of Infection & Mean age (years) \\
\hline Total & 57 & $57.9 \%$ & $10.44 \pm 1.83$ \\
\hline \multicolumn{4}{|l|}{ Gender } \\
\hline Male & 29 & $69.0 \%$ & $10.95 \pm 1.77$ \\
\hline \multirow[t]{2}{*}{ Female } & 28 & $46.4 \%$ & $9.92 \pm 1.67$ \\
\hline & UBT & mSAT & $\mathrm{S}-\mathrm{Ab}$ \\
\hline Sensitivity & $100 \%$ & $93.3 \%$ & $95.5 \%$ \\
\hline Specificity & $76.9 \%$ & $90.9 \%$ & $100 \%$ \\
\hline $\mathrm{LR}_{+}$ & 4.33 & 10.27 & $\infty$ \\
\hline $\mathrm{LR}_{-}$ & 0 & 0.73 & 0.045 \\
\hline Accuracy & $92.7 \%$ & $92.3 \%$ & $97.5 \%$ \\
\hline
\end{tabular}


Continued

\begin{tabular}{cccc}
\hline Group III & Number of patients & Rate of Infection & Mean age (years) \\
Total & 68 & $95.8 \%$ & $14.48 \pm 1.21$ \\
Gender & 30 & & \\
Male & 38 & $66.7 \%$ & $14.26 \pm 1.04$ \\
Female & UBT & $57.9 \%$ & $14.66 \pm 1.32$ \\
& $97.2 \%$ & mSAT & S-Ab \\
Sensitivity & $100 \%$ & $92.9 \%$ & $100 \%$ \\
Specificity & $\infty$ & $100 \%$ & $89.5 \%$ \\
LR & 0.028 & $\infty$ & 9.50 \\
LR & $98.0 \%$ & 0.071 & 0 \\
Accuracy & $95.2 \%$ & $95.4 \%$ \\
\hline
\end{tabular}

${ }^{13} \mathrm{C}$-urea breath test, UBT; monoclonal stool antigen test, mSAT; serum antibody test, S-Ab; likelihood ratio for a positive test, $\mathrm{LR}_{+}$; likelihood ratio for a negative test, LR.

infection based on either positive histology plus either a positive rapid urease test or a positive culture. They also refer to the indication of non-invasive tests such as UBT or stool antigen test when the results of histology and rapid urease test are discordant. Because invasive tests can confirm H. pylori infection directly, they are recommended as more suitable tests for the detection of infection than non-invasive tests. However, feasible accuracy of non-invasive tests for the initial diagnosis has been presented in many reports [14]-[20]. Additionally, false results from invasive tests may occur due to patchy density of $\mathrm{H}$. pylori, active bleeding in the stomach, or the presence of other pathogens producing urease in stomach such as non-Helicobacter pylori Helicobacters [21] [22] [23].

This present study demonstrated high accuracy of non-invasive H. pylori diagnostic tests, UBT, mSAT and S-Ab, in pediatric patients as an initial diagnostic method. Sensitivity and specificity of all three tests were over $80 \%$ and the accuracy of all three tests was over $90 \%$. As seen in Table 2 and Table 3, parameter values for their performance for all three tests were similar when comparing either the results of our entire patient study group or the results of $36 \mathrm{pa}$ tients who underwent all 3 non-invasive tests. These results suggest that selection bias of non-invasive tests was allowable and might have only limited effect on results. On the other hand, the age of the tested children may affect sensitivity, specificity and accuracy as seen in Table 4 . In group I (1 to 6 years old), sensitivity for UBT and S-Ab were $83.3 \%$ and $75.0 \%$, specificity were $66.7 \%$ and $100 \%$, and accuracy were $77.8 \%$ and $87.5 \%$. UBT requires patient cooperation such as rinsing their mouths with water immediately after ingestion of ${ }^{13} \mathrm{C}$-urea to reduce the effect of oral urease producing bacteria. Therefore, it is more difficult to perform UBT in infants and toddler patients, and lower specificity has been obtained in children younger than 6 years old in past studies [18] [24]-[29]. Low sensitivity among young children with antibody tests has also been reported, and it was believed to result from immaturity of the immune response 
and to be affected by transfer of maternal IgG antibodies to $H$. pylori [14] [30] [31] [32] [33]. In contrast, Okuda and Ueda et al. showed high sensitivity of antibody tests using antigens derived from Japanese individuals among young children [19] [20]. We found low sensitivity and specificity of UBT and low sensitivity of S-Ab in Group I with 1 to 6 years old patients as previously reported. In addition, the specificity of UBT and the sensitivity of S-Ab increased in older groups. Conversely, the sensitivity and specificity of mSAT in same group was $100 \%$. Our results suggest more accuracy of mSAT than other non-invasive tests among young children.

In Japan, the increasing incidence of clarithromycin (CAM) resistance in $H$. pylori results in decreasing $H$. pylori eradication rates which have fallen to approximately $75 \%$ with a first line regimen with CAM [34] [35]. The prevalence of CAM resistance in young patients ranges from $29 \%-43.4 \%$ in Japan [36] [37] [38] [39] [40]. Thus, clinical guidelines recommend antibiotic susceptibility testing for CAM prior to initial eradication therapy in children due to the high resistance rate $(>20 \%)$ as clinical guidelines [13]. Therefore, 4 biopsies ( 2 for histology, 1 for rapid urease test, and 1 for culture and susceptibility testing) from both the antrum and the corpus are required to diagnose $H$. pylori infection and to prevent false results due to patchy density of $H$. pylori according to clinical guidelines [13]. Our study demonstrates reliable performance by non-invasive tests, $\mathrm{UBT}, \mathrm{mSAT}$ and $\mathrm{S}-\mathrm{Ab}$, in pediatric patients for initial diagnosis of $H$. pylori. Histological findings are needed to confirm causes of symptoms indicating EGDs. However, a rapid urease test could only contribute to the detection of $H$. pylori infection. Consequently, we propose replacing a rapid urease test with a non-invasive test in children to reduce invasion by EGDs and to limit the taking of biopsies as much as possible. We can select non-invasive tests according to risk factors leading to false results such as age of patient, history of administration and stool condition.

In conclusion, all three non-invasive tests, UBT, mSAT and S-Ab, showed sufficient sensitivity, specificity and accuracy for the initial diagnosis of $H$. pylori in children. Non-invasive tests may contribute to achieving $H$. pylori diagnosis with reduced invasion when combined with a histological test and a culture test.

\section{References}

[1] Hatakeyama, M. and Higashi, H. (2005) Helicobacter Pylori CagA: A New Paradigm for Bacterial Carcinogenesis. Cancer Science, 96, 835-843. https://doi.org/10.1111/j.1349-7006.2005.00130.x

[2] Kato, S., Kikuchi, S. and Nakajima, S. (2008) When Does Gastric Atrophy Develop in Japanese Children. Helicobacter, 13, 278-281. https://doi.org/10.1111/j.1523-5378.2008.00611.x

[3] Sugano, K., Tack, J., Kuipers, E.J., Graham, D.Y., El-Omar, E.M., Miura, S., Haruma, K., Asaka, M., Uemura, N. and Malfertheiner, P. (2015) Kyoto Global Consensus Report on Helicobacter Pylori Gastritis. Gut, 64, 1353-1367. https://doi.org/10.1136/gutjnl-2015-309252

[4] Take, S., Mizuno, M., Ishiki, K., Nagahara, Y., Yoshida, T., Yokota, K. and Oguma, 
K. (2007) Baseline Gastric Mucosal Atrophy Is a Risk Factor Associated with the Development of Gastric Cancer after Helicobacter Pylori Eradication Therapy in Patients with Peptic Ulcer Diseases. Journal of Gastroenterology, 17, 21-27. https://doi.org/10.1007/s00535-006-1924-9

[5] Wong, B.C., Lam, S.K., Wong, W.M., Chen, J.S., Zheng, T.T., Feng, R.E., Lai, K.C., Hu, W.H., Yuen, S.T., Leung, S.Y., Fong, D.Y., Ho, J., Ching, C.K. and Chen, J.S. (2004) Helicobacter Pylori Eradication to Prevent Gastric Cancer in a High-Risk Region of China: A Randomized Controlled Trial. JAMA, 291, 187-194.

https://doi.org/10.1001/jama.291.2.187

[6] Kato, S., Ozawa, K., Konno, M., Tajiri, H., Yoshimura, N., Shimizu, T., Fujisawa, T., Abukawa, D., Minoura, T. and Iinuma, K. (2002) Diagnostic Accuracy of the 13C-Urea Breath Test for Childhood Helicobacter Pylori Infection: A Multicenter Japanese Study. The American Journal of Gastroenterology, 97, 1668-1673.

https://doi.org/10.1111/j.1572-0241.2002.05825.x

[7] Feydt-Schmidt, A., Russmann, H., Lehn, N., Fischer, A., Antoni, I., Stork, D. and Koletzko, S. (2002) Fluorescence in Situ Hybridization vs. Epsilometer Test for Detection of Clarithromycin-Susceptible and Clarithromycin-Resistant Helicobacter pylori Strains in Gastric Biopsies from Children. Alimentary Pharmacology \& The rapeutics, 16, 2073-2079.https://doi.org/10.1046/j.1365-2036.2002.01382.x

[8] Ni, Y.H., Lin, J.T., Huang, S.F., Yang, J.C. and Chang, M.H. (2000) Accurate Diagnosis of Helicobacter Pylori Infection by Stool Antigen Test and 6 Other Currently Available Tests in Children. Journal of Pediatrics, 136, 823-827.

https://doi.org/10.1016/s0016-5085(00)80983-x

[9] Gatta, L., Vakil, N., Ricci, C., Osborn, J.F., Tampieri, A., Perna, F., Miglioli, M. and Vaira, D. (2004) Effect of Proton Pump Inhibitors and Antacid Therapy on 13C Urea Breath Tests and Stool Test for Helicobacter Pylori Infection. The American Journal of Gastroenterology, 99, 823-829. https://doi.org/10.1111/j.1572-0241.2004.30162.x

[10] Graham, D.Y., Opekun, A.R., Hammoud, F., Yamaoka, Y., Reddy, R., Osato, M.S. and El-Zimaity, H.M. (2003) Studies Regarding the Mechanism of False Negative Urea Breath Tests with Proton Pump Inhibitors. The American Journal of Gastroenterology, 98, 1005-1009. https://doi.org/10.1111/j.1572-0241.2003.07426.x

[11] Graham, D.Y., Opekun, A.R., Jogi, M., Yamaoka, Y., Lu, H., Reddy, R. and El-Zimaity, H.M. (2004) False Negative Urea Breath Tests with H2-Receptor Antagonists: Interactions between Helicobacter pylori Density and pH. Helicobacter, 9 , 17-27. https://doi.org/10.1111/j.1083-4389.2004.00191.x

[12] Koletzko, S. (2005) Noninvasive Diagnostic Tests for Helicobacter pylori Infection in Children. Canadian Journal of Gastroenterology, 19, 433-439.

[13] Koletzko, S., Jones, N.L., Goodman, K.J., Gold, B., Rowland, M., Cadranel, S., Chong, S., Colletti, R.B., Casswall, T., Elitsur, Y., Guarner, J., Kalach, N., Madrazo, A., Megraud, F., Oderda, G. and $\mathrm{H}$ pylori Working Groups of ESPGHAN and NASPGHAN (2011) Evidence-Based Guidelines from ESPGHAN and NASPGHAN for Helicobacter pylori Infection in Children. Journal of Pediatric Gastroenterology and Nutrition, 53, 230-243.

[14] Frenck, R.W., Fathy, H.M., Sherif, M., Mohran, Z., El Mohammedy, H., Francis, W., Rockabrand, D., Mounir, B.I., Rozmajzl, P. and Frierson, H. F. (2006) Sensitivity and Specificity of Various Tests for the Diagnosis of Helicobacter pylori in Egyptian Children. Pediatrics, 118, e1195-1202. https://doi.org/10.1542/peds.2005-2925

[15] Leal, Y.A., Flores, L.L., Fuentes-Panana, E.M., Cedillo-Rivera, R. and Torres, J. (2011) 13C-Urea Breath Test for the Diagnosis of Helicobacter pylori Infection in 
Children: A Systematic Review and Meta-Analysis. Helicobacter, 16, 327-337. https://doi.org/10.1111/j.1523-5378.2011.00863.x

[16] Leal, Y.A., Cedillo-Rivera, R., Simon, J.A., Velazquez, J.R., Flores, L.L. and Torres, J. (2011) Utility of Stool Sample-Based Tests for the Diagnosis of Helicobacter pylori Infection in Children. Journal of Pediatric Gastroenterology and Nutrition, 52, 718728. https://doi.org/10.1097/MPG.0b013e3182077d33

[17] Okuda, M., Osaki, T., Kikuchi, S., Ueda, J., Lin, Y., Yonezawa, H., Maekawa, K., Hojo, F., Kamiya, S. and Fukuda, Y. (2014) Evaluation of a Stool Antigen Test Using a mAb for Native Catalase for Diagnosis of Helicobacter pylori Infection in Children and Adults. Journal of Medical Microbiology, 63, 1621-1625. https://doi.org/10.1099/jmm.0.077370-0

[18] Megraud, F. and European Paediatric Task Force on Helicobacter (2005) Comparison of Non-Invasive Tests to Detect Helicobacter pylori Infection in Children and Adolescents: Results of a Multicenter European Study. Journal of Pediatrics, 146, 198-203.

[19] Okuda, M., Sugiyama, T., Fukunaga, K., Kondou, M., Miyashiro, E. and Nakazawa, T. (2005) A Strain-Specific Antigen in Japanese Helicobacter pylori Recognized in Sera of Japanese Children. Clinical and Diagnostic Laboratory Immunology, 12, 1280-1284. https://doi.org/10.1128/cdli.12.11.1280-1284.2005

[20] Ueda, J., Okuda, M., Nishiyama, T., Lin, Y., Fukuda, Y. and Kikuchi, S. (2014) Diagnostic Accuracy of the E-Plate Serum Antibody Test Kit in Detecting Helicobacter pylori Infection among Japanese Children. Journal of Epidemiology, 24, 47-51. https://doi.org/10.2188/jea.JE20130078

[21] Borrelli, O., Hassall, E., D’Armiento, F., Bosco, S., Mancini, V., Di Nardo, G., Bueno de Mesquita, M. and Cucchiara, S. (2003) Inflammation of the Gastric Cardia in Children with Symptoms of Acid Peptic Disease. Journal of Pediatrics, 143, 520524. https://doi.org/10.1067/S0022-3476(03)00392-5

[22] Gisbert, J.P. and Abraira, V. (2006) Accuracy of Helicobacter pylori Diagnostic Tests in Patients with Bleeding Peptic Ulcer: A Systematic Review and Meta-Analysis. The American Journal of Gastroenterology, 101, 848-863. https://doi.org/10.1111/j.1572-0241.2006.00528.x

[23] Yakoob, J., Abbas, Z., Khan, R., Naz, S., Ahmad, Z., Islam, M., Awan, S., Jafri, F. and Jafri, W. (2012) Prevalence of Non Helicobacter pylori Species in Patients Presenting with Dyspepsia. BMC Gastroenterology, 12, 3. https://doi.org/10.1186/1471-230X-12-3

[24] De Carvalho Costa Cardinali, L., Rocha, G.A., Rocha, A.M., de Moura, S.B., de Figueiredo Soares, T., Esteves, A.M., Nogueira, A.M., Cabral, M.M., de Carvalho, A.S., Bitencourt, P., Ferreira, A. and Queiroz, D.M. (2003) Evaluation of [13C] urea Breath Test and Helicobacter pylori Stool Antigen Test for Diagnosis of H. pylori Infection in Children from a Developing Country. Journal of Clinical Microbiology, 41, 3334-3335. https://doi.org/10.1128/JCM.41.7.3334-3335.2003

[25] Dondi, E., Rapa, A., Boldorini, R., Fonio, P., Zanetta, S. and Oderda, G. (2006) High Accuracy of Noninvasive Tests to Diagnose Helicobacter pylori Infection in Very Young Children. Journal of Pediatrics, 149, 817-821.

[26] Imrie, C., Rowland, M., Bourke, B. and Drumm, B. (2001) Limitations to Carbon 13-Labeled Urea Breath Testing for Helicobacter pylori in Infants. Journal of Pediatrics, 139, 734-737. https://doi.org/10.1067/mpd.2001.118398

[27] Kindermann, A., Demmelmair, H., Koletzko, B., Krauss-Etschmann, S., Wiebecke, B. and Koletzko, S. (2000) Influence of Age on 13C-Urea Breath Test Results in Children. Journal of Pediatric Gastroenterology and Nutrition, 30, 85-91. 
https://doi.org/10.1097/00005176-200001000-00023

[28] Machado, R.S., Patricio, F.R. and Kawakami, E. (2004) 13C-Urea Breath Test to Diagnose Helicobacter pylori Infection in Children Aged up to 6 Years. Helicobacter, 9, 39-45. https://doi.org/10.1111/j.1083-4389.2004.00196.x

[29] Yang, H.R. and Seo, J.K. (2005) Diagnostic Accuracy of the C-Urea Breath Test in Children: Adjustment of the Cut-Off Value According to Age. Journal of Gastroenterology and Hepatology, 20, 264-269. https://doi.org/10.1111/j.1440-1746.2004.03541.x

[30] Corvaglia, L., Bontems, P., Devaster, J.M., Heimann, P., Glupczynski, Y., Keppens, E. and Cadranel, S. (1999) Accuracy of Serology and 13C-Urea Breath Test for Detection of Helicobacter pylori in Children. The Pediatric Infectious Disease Journal, 18, 976-979. https://doi.org/10.1097/00006454-199911000-00008

[31] Gold, B.D., Khanna, B., Huang, L.M., Lee, C.Y. and Banatvala, N. (1997) Helicobacter pylori Acquisition in Infancy after Decline of Maternal Passive Immunity. Pediatric Research, 41, 641-646. https://doi.org/10.1203/00006450-199705000-00007

[32] Leal, Y.A., Flores, L.L., Garcia-Cortes, L.B., Cedillo-Rivera, R. and Torres, J. (2008) Antibody-Based Detection Tests for the Diagnosis of Helicobacter pylori Infection in Children: A Meta-Analysis. PLoS ONE, 3, e3751. https://doi.org/10.1371/journal.pone.0003751

[33] Okuda, M., Miyashiro, E., Koike, M., Tanaka, T., Bouoka, M., Okuda, S. and Yoshikawa, N. (2002) Serodiagnosis of Helicobacter pylori Infection Is Not Accurate for Children Aged below 10. Pediatrics International, 44, 387-390. https://doi.org/10.1046/j.1442-200X.2002.01585.x

[34] Kobayashi, I., Murakami, K., Kato, M., Kato, S., Azuma, T., Takahashi, S., Uemura, N., Katsuyama, T., Fukuda, Y., Haruma, K., Nasu, M. and Fujioka, T. (2007) Changing Antimicrobial Susceptibility Epidemiology of Helicobacter pylori Strains in Japan between 2002 and 2005. Journal of Clinical Microbiology, 45, 4006-4010. https://doi.org/10.1128/JCM.00740-07

[35] Nishizawa, T., Maekawa, T., Watanabe, N., Harada, N., Hosoda, Y., Yoshinaga, M., Yoshio, T., Ohta, H., Inoue, S., Toyokawa, T., Yamashita, H., Saito, H., Kuwai, T., Katayama, S., Masuda, E., Miyabayashi, H., Kimura, T., Nishizawa, Y., Takahashi, M. and Suzuki, H. (2015) Clarithromycin versus Metronidazole as First-Line Helicobacter pylori Eradication: A Multicenter, Prospective, Randomized Controlled Study in Japan. Journal of Clinical Gastroenterology, 49, 468-471.

[36] Kato, S. and Fujimura, S. (2010) Primary Antimicrobial Resistance of Helicobacter pylori in Children during the Past 9 Years. Pediatrics International, 52, 187-190. https://doi.org/10.1111/j.1442-200X.2009.02915.x

[37] Kato, S., Fujimura, S., Udagawa, H., Shimizu, T., Maisawa, S., Ozawa, K. and Iinuma, K. (2002) Antibiotic Resistance of Helicobacter pylori Strains in Japanese Children. Journal of Clinical Microbiology, 40, 649-653. https://doi.org/10.1128/JCM.40.2.649-653.2002

[38] Kato, S., Konno, M., Maisawa, S., Tajiri, H., Yoshimura, N., Shimizu, T., Toyoda, S., Nakayama, Y. and Iinuma, K. (2004) Results of Triple Eradication Therapy in Japanese Children: A Retrospective Multicenter Study. Journal of Gastroenterology, 39, 838-843. https://doi.org/10.1007/s00535-004-1398-6

[39] Okamura, T., Suga, T., Nagaya, T., Arakura, N., Matsumoto, T., Nakayama, Y. and Tanaka, E. (2014) Antimicrobial Resistance and Characteristics of Eradication Therapy of Helicobacter pylori in Japan: A Multi-Generational Comparison. Helicobacter, 19, 214-220. https://doi.org/10.1111/hel.12124

[40] Okuda, M., Kikuchi, S., Mabe, K., Osaki, T., Kamiya, S., Fukuda, Y. and Kato, M. 
(2017) Nationwide Survey of Helicobacter pylori Treatment for Children and Adolescents in Japan. Pediatrics International, 59, 57-61.

https://doi.org/10.1111/ped.13038

Submit or recommend next manuscript to SCIRP and we will provide best service for you:

Accepting pre-submission inquiries through Email, Facebook, LinkedIn, Twitter, etc. A wide selection of journals (inclusive of 9 subjects, more than 200 journals)

Providing 24-hour high-quality service

User-friendly online submission system

Fair and swift peer-review system

Efficient typesetting and proofreading procedure

Display of the result of downloads and visits, as well as the number of cited articles Maximum dissemination of your research work

Submit your manuscript at: http://papersubmission.scirp.org/

Or contact aim@scirp.org 